\title{
Tidal influences on humpback whale habitat selection near headlands
}

\author{
Ellen M. Chenoweth ${ }^{1, *}$, Christine M. Gabriele ${ }^{1}$, David F. Hill ${ }^{2}$ \\ ${ }^{1}$ Glacier Bay National Park, 1 Park Road, Gustavus, Alaska 99826, USA \\ ${ }^{2}$ Oregon State University, 207 Owen Hall, Corvallis, Oregon 97330, USA
}

\begin{abstract}
In order to design marine protected areas that are ecologically meaningful, it would be useful to improve our understanding of headland wake foraging systems, which are commonly exploited by baleen whales and other mobile marine predators. We used humpback whale Megaptera novaeangliae sighting data from 1997 to 2008 in combination with tidal prediction software to investigate the effects of current direction (ebb vs. flood) and tidal amplitude on the distribution and abundance of humpback whales around 3 headlands and 5 non-headlands in Glacier Bay and Icy Strait in southeastern Alaska, USA. Headlands were defined as points of land that disrupt tidal flow creating distinct tideward and leeward conditions. We used an advanced tidal circulation model (ADCIRC) to identify these conditions. Current direction and tidal amplitude each significantly affected whale distribution at only one non-headland $\left(\chi^{2}=6.1, \mathrm{p}<0.01 ; \chi^{2}=13, \mathrm{p}=0.002\right.$, respectively). At all 3 headlands, current direction significantly affected whale distribution $(\mathrm{p}<0.0001)$. Whale abundance was greater in the leeward areas. Tidal amplitude significantly affected distribution at the 3 headlands $\left(\chi^{2}=97, \mathrm{p}<0.0001 ; \chi^{2}=75, \mathrm{p}<0.0001 ; \chi^{2}=6.1, \mathrm{p}=0.05\right)$ such that whales selected habitat that moderated, rather than maximized, the effect of tidal amplitude, suggesting that headlands also have the potential to be important features in areas with less extreme tidal exchange.
\end{abstract}

KEY WORDS: Habitat selection · Headland wake · Humpback whale $\cdot$ Foraging · Tidal currents · Hydrodynamic modeling

\section{INTRODUCTION}

Oceanographic features that arise from interactions between winds, tidal currents, and topography are known to create biological aggregations (Wolanski \& Hamner 1988, Wolanski et al. 1996). Diurnal and monthly cycles of tidal currents make these oceanographic features somewhat predictable in time so that marine mammals and seabirds gather to exploit the resulting elevated concentrations of zooplankton and small fish. Headlands, islands and reefs that create 3dimensional 'island wake' ecosystems (Wolanski \& Hamner 1988, Johnston et al. 2005b) can aggregate biological organisms at multiple trophic levels.

High latitude systems, which are characterized by exceptionally large and variable tidal amplitudes, appear to accentuate the tidal component, such that many studies of these biological aggregations occur there. For example, rorquals feed on tidally aggregated krill along a shoreline in the St. Lawrence estuary (Cotté \& Simard 2005), short-tailed shearwaters Puffinus tenuirostris gather at tidal fronts in the Aleutian Islands (Vlietstra et al. 2005), harbor seals Phoca vitulina forage during flood tide at a channel constriction in the San Juan Islands (Zamon 2001), bottlenose dolphins Tursiops truncatus feed at a tidal intrusion into a river in northeast Scotland (Mendes et al. 2002) and forage between headlands in the Moray Firth (Hastie et al. 2003), and harbor porpoises Phocoena phocoena (Johnston et al. 2005b) and rorquals (Johnston et al. 2005a, Johnston \& Read 2007) feed at an island wake system in the Bay of Fundy. Here, we investigate whether cyclic changes in tidal amplitude and direction at headlands create fine scale $(1-10 \mathrm{~km}$, after Johnston et al. 2005b) micro-habitats that are systematically exploited by foraging humpback whales 
Megaptera novaeangliae in a high latitude glacial fjord system in Alaska, USA.

Many marine mammals and seabirds depend on patchy, dispersed prey that is highly variable in space and time, while facing high metabolic demands due to factors such as large body size, endothermy and flight. Because each prey item yields a relatively small energetic reward, natural selection would seem to favor marine predators that identify and exploit recurrent prey aggregations, thereby increasing the number of captures per unit of search effort. For example, shearwaters will select smaller fish if the fish are more tightly aggregated; apparently accepting a smaller energetic reward when foraging is less energetically demanding (Vlietstra et al. 2005). Robards et al. (2003) concluded that less than $8 \%$ of Glacier Bay and Icy Strait waters contain prey aggregations sufficiently dense (0.1 fish $\mathrm{m}^{-3}$, Robards et al. 2002) to be profitable for foraging marine mammals and sea birds. Humpback whales will only aggregate to feed at a certain threshold of prey density, which varies annually depending on the overall prey availability (Piatt \& Methven 1992).

The metabolic challenges created by their large body size, migratory life history, and energetically demanding foraging behavior make humpback whales particularly sensitive to prey density and therefore an excellent candidate for studying how subtle variation in tidal conditions affect habitat selection. Humpback whales are large baleen whales that undergo a seasonal fast and migrate to wintering grounds for breeding and calving (Dawbin 1966). In southeastern Alaska, humpback whales have strong, maternally directed site fidelity to feeding areas (Baker et al. 1998), where they spend spring, summer and fall foraging on small schooling fish and euphausiids. In the Glacier Bay and Icy Strait glacial fjord system, humpback whales feed primarily on small schooling fish such as Pacific herring Clupea pallasii, capelin Mallotus villosus, Pacific sand lance Ammodytes hexapterus and juvenile walleye pollock Theragra chalcogramma (Wing \& Krieger 1983, Krieger \& Wing 1984). Humpback whales and other rorquals capture prey by actively accelerating through prey patches and passively decelerating as they open their mouths to feed. This feeding style is thought to be more energetically demanding than skim-feeding strategies used by other baleen whales (Goldbogen et al. 2008).

Theoretically, when a headland interacts with tidal currents, 2 distinct micro-habitats are created. The tideward side faces the incoming current while the leeward side, also known as the headland wake, is sheltered by the headland itself. When the tide changes direction from ebb to flood or flood to ebb, the tideward and leeward sides switch. Shorelines of a head- land can be consistently identified as 'tideward at ebb' or 'tideward at flood.' The leeward side experiences complex downstream current patterns, particularly eddies, which may be relatively stable or may move, disperse and reform less predictably (Wolanski \& Hamner 1988). The structure of eddies theoretically depends on factors such as water depth, current speed and the extent to which a headland intrudes into the tidal flow (Wolanski \& Hamner 1988). These current patterns can cause upwelling and the concentration of plankton and fish larvae (Wolanski et al. 1996). In the Bay of Fundy, minke and fin whales (Balaenaptera acutorostratus and B. physalus, respectively) were found to forage in an eddy that forms on the leeward side of an island during a flood tide (Johnston et al. 2005a, Johnston \& Read 2007).

Many previous studies (Mendes et al. 2002, Cotté \& Simard 2005, Johnston et al. 2005a,b, Vlietstra et al. 2005) demonstrate a clear relationship between foraging behavior and the diurnal tide cycle. Hastie et al. (2003) found no such correlation between abundance of bottlenose dolphins between 2 points of land, but did not look for changes in distribution. The potentially important contribution of the near-monthly changes in tidal amplitude has not been adequately considered (Mendes et al. 2002, Johnston et al. 2005a). In addition, because each of these studies focused on a specific oceanic feature in isolation from its surroundings, it is difficult to assess the habitat selection choices faced by the predator in question, or to understand the ecological factors that could contribute to fine-scale variations in habitat quality.

In this study, we investigate the effects of cyclic changes in tidal direction and amplitude on foraging humpback whales by comparing the distribution and abundance of whales sighted at multiple headlands and non-headland shorelines over a 12 yr period, in combination with ADCIRC (Advanced CIRCulation model) (Luettich \& Westerink 1991) to identify tideward and leeward conditions. We hypothesize that current speed and direction are important factors affecting humpback whale micro-habitat selection at headlands.

\section{MATERIALS AND METHODS}

Study area. This study took place in Glacier Bay and adjacent Icy Strait in southeastern Alaska. Glacier Bay is a glacial fjord-estuarine system comprised of over $2434 \mathrm{~km}^{2}$ of marine waters that open into Icy Strait. Glacier Bay and Icy Strait serve as the summer feeding ground for over 150 humpback whales (Neilson \& Gabriele 2008) that are part of the southeastern Alaska feeding stock, which is currently estimated at 3000 to 
5000 individuals (Calambokidis et al. 2008). Glacier Bay and Icy Strait experience a mixed semidiurnal tide with 2 high tides and 2 low tides of unequal heights per $24 \mathrm{~h}$ period. In addition to this daily fluctuation, the tide varies around a lunar cycle of spring tides (days with large tidal amplitudes) and neap tides (days with small tidal amplitudes). Tidal amplitude affects current speeds, with large amplitude tides resulting in faster current speeds than small amplitude tides. In addition to this temporal variation, tidal current speed also varies geographically throughout the study area. Etherington et al. (2007) computed long-term average root-mean-square (RMS) current speeds throughout Glacier Bay and Icy Strait. They found that RMS cur- rent speeds ranged from just a few $\mathrm{cm} \mathrm{s}^{-1}$ in the upper arms of Glacier Bay to $>1.2 \mathrm{~m} \mathrm{~s}^{-1}$ near the mouth of the bay and that these high current velocities were important in promoting water column mixing and reducing stratification. Finally, using a simple classification scheme developed by Friedrichs \& Aubrey (1988), we determined that Glacier Bay and Icy Strait are flooddominated systems, meaning that flood tide results in faster current velocities than ebb tide.

Identifying likely headlands and non-headland shorelines. We identified 5 points of land in lower Glacier Bay and Icy Strait that could potentially influence the flow of water (Fig. 1). As a control, we selected 5 'non-headland' areas characterized by rela-

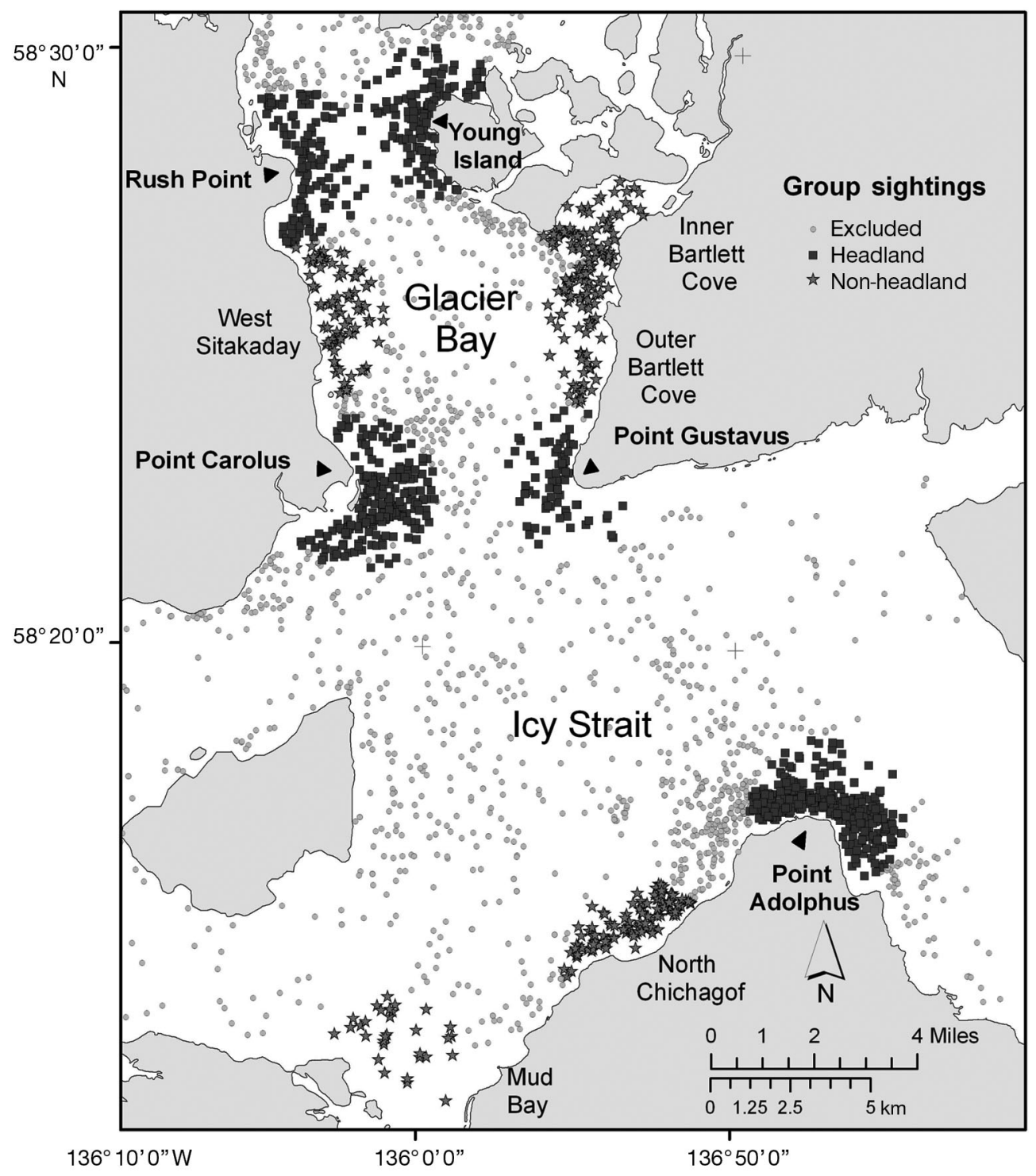

Fig. 1. Megaptera novaeangliae. Study area showing whale sightings near points of land (匹), non-headlands ( $\star$ ), or sightings omitted from analysis (०) 
tively linear shorelines or coves (Inner Bartlett Cove, Outer Bartlett Cove, West Sitakaday, Mud Bay, and North Chichagof; Fig. 1). As no literature exists to advise a suitable radius to define the extent of influence of headland wakes at possible headlands, 2.78 $\mathrm{km}$ (1.5 nautical miles) was chosen to maximize the included area while avoiding overlap between areas. Any whale sightings that occurred outside of $2.78 \mathrm{~km}$ of a designated headland or non-headland were excluded from analysis.

Hydrodynamic modeling. As the first step in identifying headlands, and in an effort to learn more about the local circulation patterns, a $90 \mathrm{~d}$ high-resolution computational tidal simulation of Glacier Bay, including the waters of Icy Strait and Cross Sound, was carried out using ADCIRC. This model is a powerful, open source, and widely used (Hill et al. 2009) tidal circulation code. ADCIRC uses an unstructured finite-element mesh for its computational domain. This mesh, a portion of which is shown in Fig. 2, is comprised of triangular elements and computational nodes, which are the vertices of the triangles. Various factors influence the size of the grid elements (Hill et al. 2009). For the present study, the mesh had approximately 40000 nodes and 80000 elements. The use of an unstructured mesh has 2 primary advantages over structured rectangular grids. First, it is able to model the complex shoreline much more accurately. Second, it allows for small elements to be placed in regions requiring high resolution, such as in shallow water. Additionally,

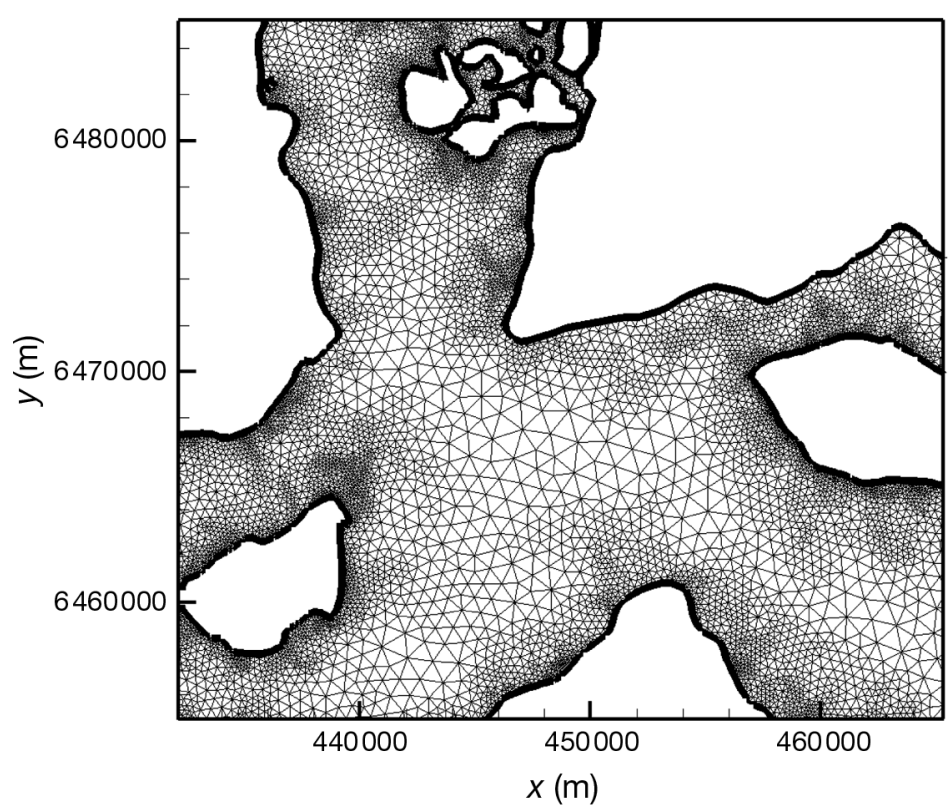

Fig. 2. Computational mesh used in the ADCIRC model for the tidal simulations in lower Glacier Bay and Icy Strait. Coordinates correspond to UTM Zone 8 Projection
ADCIRC has the ability to perform harmonic analysis on both the elevation and the velocity results. This feature allows for the determination of the amplitudes and phases of the tidal constituents. Inputs to the model include many complex factors, fully described in Hill et al. (2009). Output from the ADCIRC model includes predictions of water surface elevation and depthintegrated velocity.

We used ADCIRC to compute the RMS, a suitable average for an oscillating variable, and maximum expected tidal velocities at all grid nodes. These quantities are long-term averages over a $90 \mathrm{~d}$ simulation. Like a tidal elevation datum such as mean higher high water (MHHW), RMS current speed is considered stable over a period of a few decades. The RMS and maximum velocity fields were then interpolated to the actual whale observation locations. In addition to computing the flow statistics described above, the ADCIRC simulations are useful in understanding the complex spatial structure of the tidal flow in the study area. As an example, Fig. 3 shows a typical velocity field, at peak flood (defined here as maximum northerly flow through the bay mouth), during typical spring tide conditions. In Icy Strait, between Point Adolphus and Point Gustavus, a change in flow direction is observed. At this moment of peak flood, waters near Point Gustavus are moving slowly westward and are being entrained into the bay. However, waters near Point Adolphus are moving eastward past the headland. Note also that the vast majority of water being entrained into the bay is coming from the west, as indicated by the very strong flows around Point Carolus.

Testing for tideward and leeward habitats with RMS current speed. Headlands were defined as points of land that disrupt tidal flow creating distinct tideward and leeward conditions. It has previously been shown that current speeds on the leeward side of a headland are slower than on the tideward side (Wolanski et al. 1996). Since the tidal regime in the study area is flood-dominated, the RMS current speed at sighting locations that are tideward during flood are faster than those that are tideward during ebb. The RMS value does not reflect the conditions present at the time of a whale sighting, but rather shows the average current speed at that location over time including ebb and flood, large amplitude and small amplitude conditions. All whale sighting locations at each headland or nonheadland were categorized as either 'faster' or 'slower' based on their RMS current speed value relative to other values within that same headland wake system. ArcGIS 9.1 (Esri 2006) determined the thresholds for these categories separately at each headland through a function called 'natural breaks' which designates categorical thresholds based on the modal distribution of data to 'best group similar values and maximize the 

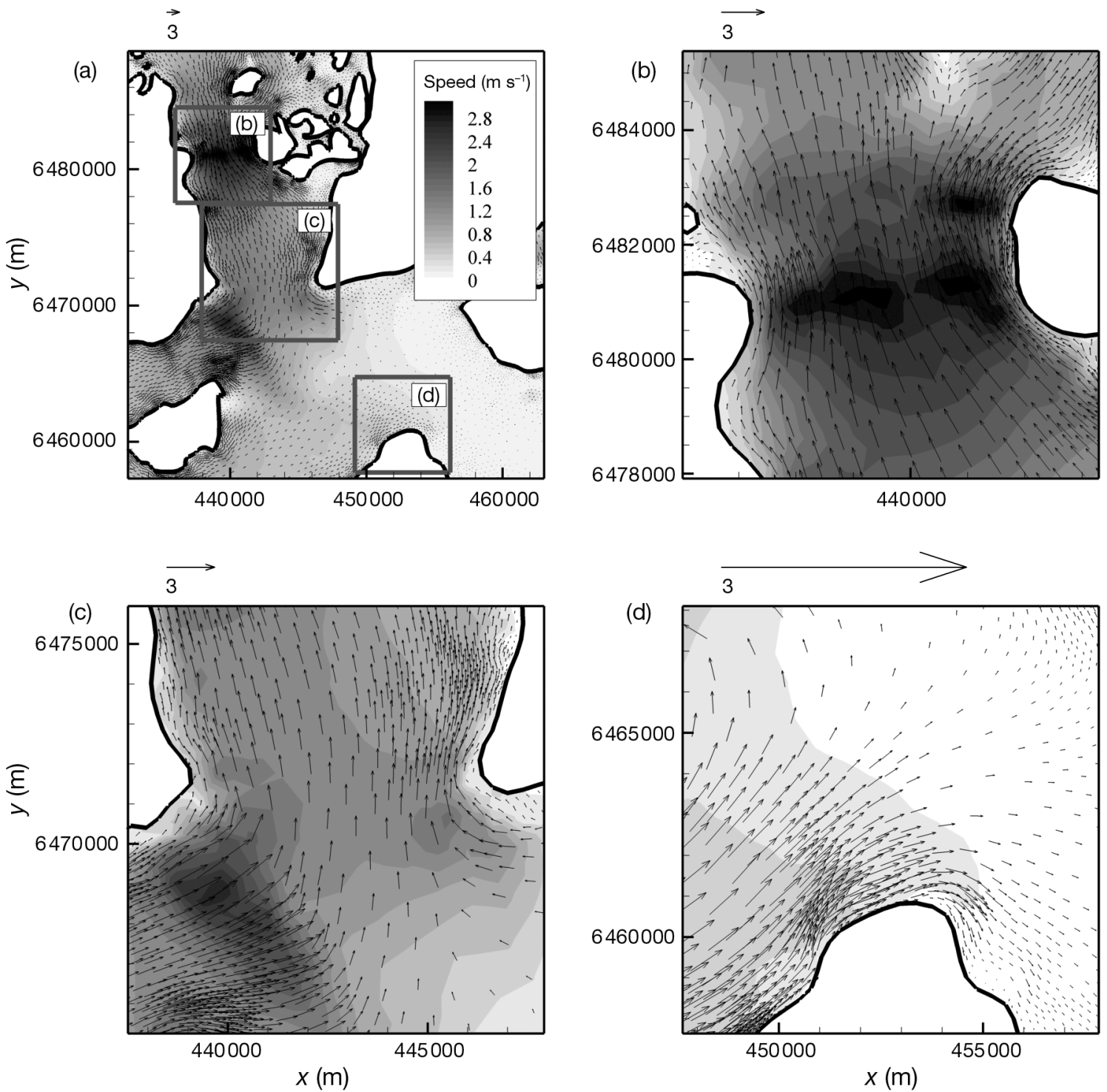

Fig. 3. Sample ADCIRC output showing the instantaneous velocity field during peak flood for a spring tide: (a) overview of lower Glacier Bay and western Icy Strait, (b) close-up of Sitakaday Narrows including Rush Point (left) and Young Point (right), (c) close-up of the mouth of Glacier Bay including Point Carolus (left) and Point Gustavus (right), (d) close-up of Point Adolphus. Gray scale contours show the magnitude of the tidal velocity vector; gray scale map is the same for all plots. Vectors show the direction and magnitude of flow, and have been rescaled in each plot to maximize clarity. For each plot, a reference vector, indicating a velocity of $3 \mathrm{~m} \mathrm{~s}^{-1}$, has been provided (arrow above each panel)

differences between classes.' Because current speed is highly variable among headlands (Table 1), a sighting location in the 'faster' RMS current speed category at Point Adolphus would likely have a 'slower' RMS current speed than a sighting in the slower category at Point Carolus because Point Carolus generally experiences faster currents. 'Faster' and 'slower' RMS current categories are useful because they show how currents at one sighting location compare to others in their immediate vicinity, which will become important when determining whether a point creates distinct tideward and leeward habitat and therefore will be considered a headland. It also allows us to compare patterns of heterogeneity between headlands of different overall current speeds.

Whale surveys. Standardized photographic identification surveys lasting approximately $8 \mathrm{~h}$ were conducted 4 to $5 \mathrm{~d}$ a week in June, July and August. These surveys documented the number of individual humpback whales in Glacier Bay and Icy Strait, as well as their residence times, spatial and temporal distributions, reproductive parameters and feeding behaviors (Neilson \& Gabriele 2008). Surveys attempted to cover Glacier Bay and Icy Strait evenly over the course of 
Table 1. Summary statistics for hydrodynamics at headlands and non-headlands, and number of Megaptera novaeangliae sightings. Threshold root-mean-square (RMS) refers to the RMS speed value that divides the faster locations around each headland or non-headland from the slower locations

\begin{tabular}{|c|c|c|c|c|c|c|c|c|c|}
\hline & \multirow{3}{*}{$\begin{array}{c}\text { Threshold } \\
\text { RMS } \\
\left(\mathrm{m} \mathrm{s}^{-1}\right)\end{array}$} & \multirow{3}{*}{$\begin{array}{l}\text { Variance of } \\
\text { RMS current } \\
\text { speed }\left(\mathrm{m} \mathrm{s}^{-1}\right)\end{array}$} & \multirow{3}{*}{$\begin{array}{l}\text { Max. current } \\
\text { speed } \\
\left(\mathrm{m} \mathrm{s}^{-1}\right)\end{array}$} & \multirow{3}{*}{$\begin{array}{c}\text { Whale sighting } \\
\text { locations } \\
\left(\mathrm{m} \mathrm{s}^{-1}\right)\end{array}$} & \multirow{3}{*}{$\begin{array}{c}\text { Total } \\
\text { whales }\end{array}$} & \multicolumn{4}{|c|}{ Total whales sighted in: } \\
\hline & & & & & & 'faster' & locations & 'slower & locations \\
\hline & & & & & & Ebb & Flood & $\mathrm{Ebb}$ & Flood \\
\hline \multicolumn{10}{|l|}{ Headland } \\
\hline Point Adolphus & 0.17 & 0.0038 & 0.69 & 414 & 911 & 238 & 365 & 35 & 273 \\
\hline Point Carolus & 0.87 & 0.056 & 3.0 & 266 & 488 & 163 & 89 & 67 & 169 \\
\hline Young Point & 0.77 & 0.14 & 3.5 & 147 & 197 & 49 & 65 & 10 & 73 \\
\hline \multicolumn{10}{|l|}{ Non-headland } \\
\hline Inner Bartlett Cove & 0.059 & 0.0024 & 0.58 & 70 & 90 & 11 & 37 & 20 & 22 \\
\hline Mud Bay & 0.90 & 0.0026 & 0.76 & 32 & 44 & 3 & 28 & 4 & 9 \\
\hline N. Chichagof Island & 0.86 & 0.0009 & 0.71 & 108 & 148 & 27 & 26 & 45 & 50 \\
\hline Outer Bartlett Cove & 0.24 & 0.0079 & 0.96 & 77 & 100 & 23 & 18 & 29 & 30 \\
\hline W. Sitakaday & 2.2 & 0.0096 & 2.2 & 87 & 132 & 28 & 41 & 24 & 39 \\
\hline
\end{tabular}

each week and to maximize the number of whales identified. The study area was too large to survey in $1 \mathrm{~d}$ and was therefore divided into sub-areas. If there were few or no whales in the sub-area during a survey day, then another area was surveyed, making the protocol adaptable to variability in whale abundance and distribution. During a whale survey, researchers in a small outboard-driven motorboat located whales by spotting their blows, approached them, photographed them for individual identification and noted their behavior. The current study used 1997 to 2008 whale location and group size data from this monitoring dataset. We chose to focus on the Lower Bay and Icy Strait, a $400 \mathrm{~km}^{2}$ area. Humpback whales are most abundant there (Neilson \& Gabriele 2008), and it includes a range of current speeds including the fastest in Glacier Bay (Etherington et al. 2007). The vast majority of surveys occurred between 08:00 and 16:00 h. As a result of long-term uneven distribution in the timing of high and low tides, survey effort was biased with $58 \%$ of survey time occurring during flood and only $42 \%$ occurring during ebb.

Determining tidal amplitude and current direction. Since tidal current conditions were not recorded in the field, and it was not practical to use ADCIRC modeling for $12 \mathrm{yr}$ of sightings, we used the computer program Tides and Currents for Windows 2.0a (Nautical Software, 1993-1995) to retroactively determine whether each whale sighting occurred during an ebb or a flood tide and during a large, intermediate or small amplitude tide. We defined slack tide as currents of $<0.1$ knots. We chose not to analyze sightings during slack tide because of the small sample size for this relatively short period of time. Large tidal amplitude was equal to or greater than the mean spring tide $(5.7 \mathrm{~m}$ in Bartlett Cove), small was equal to or smaller than the mean neap tide (3.7 $\mathrm{m}$ in Bartlett Cove), and intermediate tide included all other values. We analyzed predictions for Bartlett Cove because it was centrally located. The tide change at most places occurred within a few minutes of Bartlett Cove and at all places within the duration of a spring slack tide (ca. $15 \mathrm{~min}$ ).

Data analysis. We performed ANOVA with TukeyKramer HSD post hoc tests to identify differences between the proportion of annual whale sightings in the study area that occurred at each headland and non-headland. We used proportion of annual sightings since the total number of whale sightings varied quite a bit and generally increased through the years (Neilson \& Gabriele 2008). We then examined potential differences in humpback whale distribution between 'faster' and 'slower' RMS current speed locations at each headland and non-headland during ebb versus flood currents with Pearson's $\chi^{2}$ tests. We repeated this analysis for large, intermediate and small amplitude tides. We then compared the results qualitatively looking for similar patterns among significant results.

\section{RESULTS}

\section{Identifying headland wake systems}

Three points of land (Point Adolphus, Point Carolus, and Young Point) were found to be headland wake systems based on the criteria of distinct tideward and leeward habitat as evidenced by 'faster' and 'slower' RMS locations concentrated on either side of the furthest land projection (Fig. 4). In all 3 cases, the 'faster' locations occur on the side of the headland that is tideward at flood while the 'slower' locations occur on the 

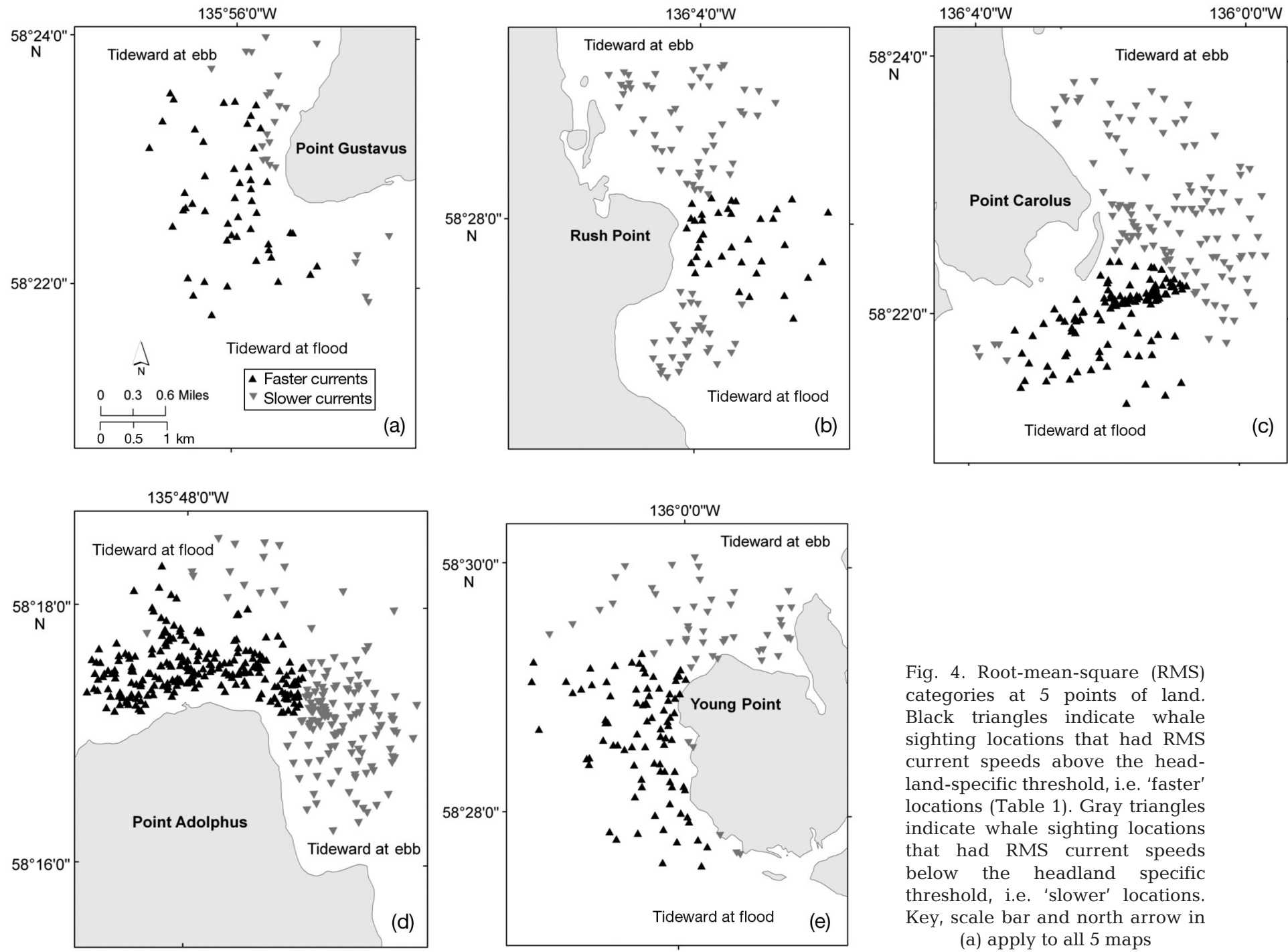

Fig. 4. Root-mean-square (RMS) categories at 5 points of land. Black triangles indicate whale sighting locations that had RMS current speeds above the headland-specific threshold, i.e. 'faster' locations (Table 1). Gray triangles indicate whale sighting locations that had RMS current speeds below the headland specific threshold, i.e. 'slower' locations. Key, scale bar and north arrow in

(a) apply to all 5 maps

side that is tideward at ebb. Point Gustavus and Rush Point were not found to be headland wake systems because 'faster' places cluster off the point itself while 'slower' locations are closer to shore (Fig. 4). The 3 headland areas combined (21.2 square miles [54.9 $\mathrm{km}^{2}$ ] of marine water) occupied $5.3 \%$ of the area of Lower Glacier Bay and Icy Strait but accounted for $24.0 \%$ of the whales sighted in the Lower Bay and Icy Strait over the 12 yr study. Summary statistics for headlands and non-headlands are found in Table 1.

\section{Relative whale abundance at headlands and non-headlands}

Whale abundance varied significantly among headland and non-headland areas $(F=21.176, \mathrm{p}<0.0001$, $\mathrm{df}=11)$. Over $12 \mathrm{yr}$, an average of $13 \%( \pm 3 \% \mathrm{SE})$ of whale sightings in the study area were made at the Point Adolphus headland. This proportion was the greatest we found and significantly different from any other headland or non-headland ( $p<0.0001$ for all pair-wise comparisons). The Point Carolus headland accounted for on average $6 \%$ of annual whale sightings $( \pm 2 \%)$, significantly different from 4 out of the 5 non-headlands ( $\mathrm{p}=0.02$ to $\mathrm{p}=0.0009$, with the exception of North Chichagof: average of $3 \% \pm 1 \%$ ). The proportion of Point Carolus whale sightings was not significantly different from Young Point headland (average of $3 \% \pm 1 \%$ ). There was no significant difference in the proportion of whale sightings at Young Point versus the non-headlands. Further, there was no significant differences in the proportion of whale sightings among any of the non-headlands, with each averaging between $3 \%( \pm 1 \%)$ and $1 \%( \pm 0.3 \%)$ of total sightings. 


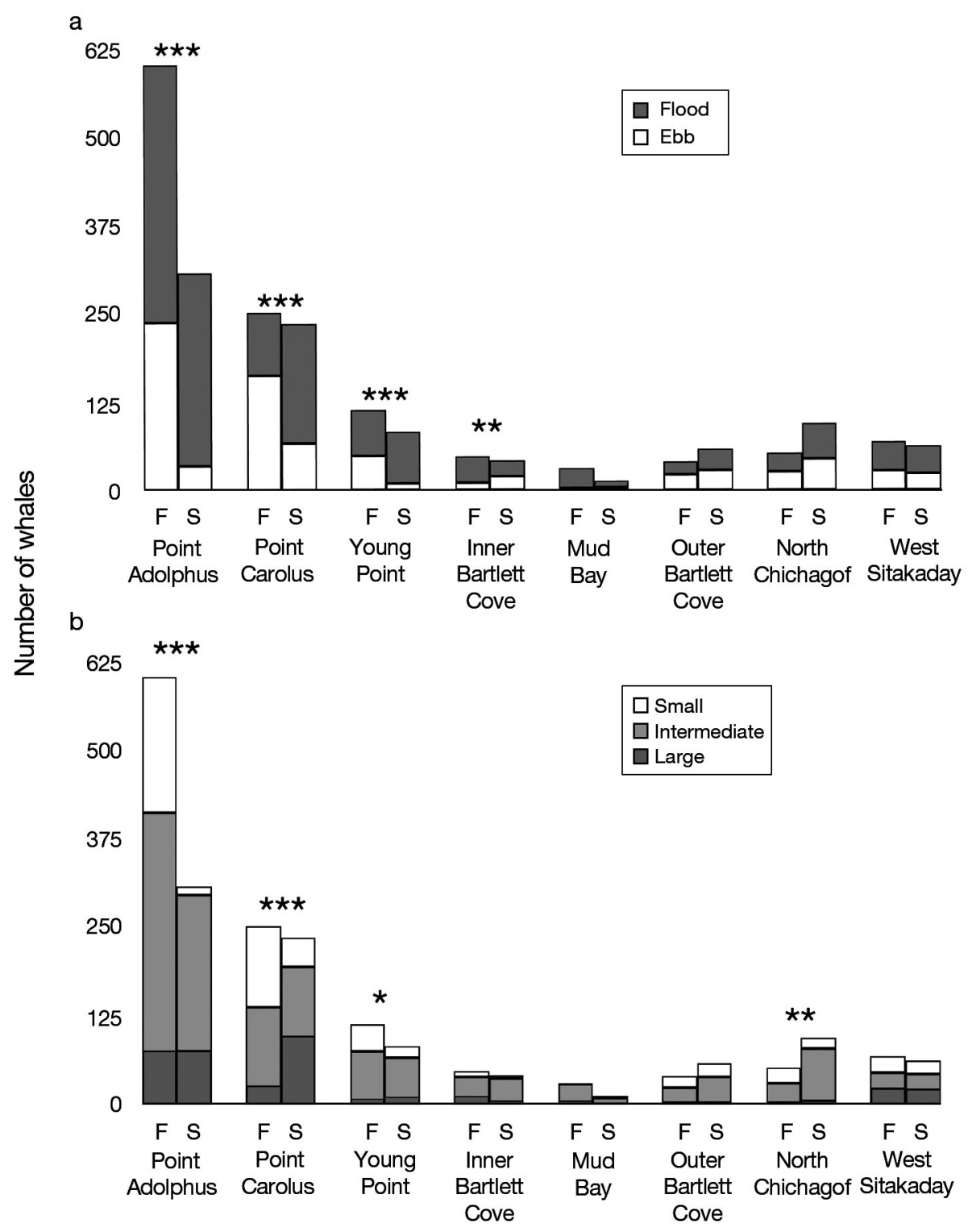

Fig. 5. Megaptera novaeangliae. Effect of (a) tide direction and (b) tidal amplitude on whale distribution. Vertical bars show the number of whales seen in 'faster' (tideward at flood: F) and 'slower' (tideward at ebb: S) locations at each of 3 headlands and 5 non-headlands (see Table 1). Significance is indicated with ${ }^{*} p<0.05,{ }^{* *} p<0.01,{ }^{* * *} p<0.001$ and no symbols for non-significant results. (a) Whales seen during a flood (gray) or ebb (white). Significance is based on $\chi^{2}$ values describing the distribution of whale sightings between 'faster' or 'slower' locations and ebb or flood conditions ( $\mathrm{df}=1)$. (b) Whales seen during a small (white), intermediate (light gray); or large (dark gray) amplitude tide. Significance is based on $\chi^{2}$ values describing the distribution of whale sightings between 'faster' or 'slower' locations and large, intermediate or small tidal amplitudes $(\mathrm{df}=2)$

\section{Effect of current direction on whale distribution}

All 3 headlands showed a significant relationship between whale distribution and current direction (Fig. 5a). Moreover, they generally shared 2 characteristics: (1) more whales in 'faster' places than in 'slower' places, and (2) more whales in leeward conditions ('faster' locations at ebb or 'slower' locations at flood) than in tideward conditions ('faster' locations at flood or 'slower' locations at ebb). Inner Bartlett Cove, an estuary and the only non-headland that had a significant result, also had more whales in 'faster' locations. But contrary to the headland pattern, it had more sightings in 'faster' locations during flood and 'slower' locations during ebb, a 'tideward' rather than 'leeward' preference (although these terms are not mean- 
ingful when applied to a non-headland). Inner Bartlett Cove differs from other non-headlands in that it is adjacent to the mouth of a river, which may be interacting with the tide to influence prey availability, including salmonid species known to inhabit the Bartlett River.

\section{Effect of tidal amplitude on whale distribution}

All 3 headlands showed a significant relationship between tidal amplitude and the likelihood of whale sightings in 'faster' or 'slower' places (Fig. 5b). Young Point's result was only marginally significant. All 3 headlands again showed similar trends, with 'slower' locations having the largest proportion of sightings for large tidal amplitudes and 'faster' location sightings predominant for small tidal amplitudes. In addition, Young Point showed borderline significance $\left(\chi^{2}=6.1\right.$, $\mathrm{df}=2, \mathrm{p}=0.05$ ) and very low numbers of whales during large amplitude tides in both 'faster' and 'slower' locations. At the North Chichagof non-headland, few whales were sighted during large amplitude tides, and were significantly more likely to be found in 'slower' locations.

\section{DISCUSSION}

Using a novel combination of a long-term humpback whale sighting database, tide prediction software, and ADCIRC tidal modeling, we identified 3 headland wake systems, and affirmed that headlands are disproportionately selected as habitat by humpback whales in Glacier Bay and Icy Strait. We further demonstrated the important role of tidal currents in mediating habitat selection at headland wake systems by showing that current direction significantly affected whale distribution around all 3 headlands. By examining whale abundance and distribution at multiple areas, we were able to highlight the unique conditions created by each headland wake system. We also demonstrated for the first time that tidal amplitude significantly affects whale abundance at 2 headland wake systems and marginally at a third. Interestingly, whales tended to select habitat that moderated, rather than amplified, fluctuations in tidal amplitude, suggesting that headlands also have the potential to be important features in areas with less extreme tidal exchange.

\section{Identifying headland wake systems}

Our method of quantitatively defining headland wake systems using ADCIRC modeling showed that not all points of land demonstrate the attributes of a headland wake system. Geography and tidal current path are important determinants of whether a given point of land will exhibit the characteristics of a headland wake system. Of the 5 points of land that we identified as possible headlands, only 3 created distinct tideward and leeward habitats. The ADCIRC tidal model illustrates why Point Gustavus and Rush Point did not have distinct tideward and leeward habitats. At Point Gustavus on flood tide (Fig. 3c), some of the water south of the point comes from the east and some comes from the west rather than straight across the point, so Point Gustavus does not appear to disrupt the flow of water as dramatically as the true headlands. At Rush Point, because of Glacier Bay's large tidal range and the shallow bathymetry around this point, the contact line between the water and land advances and retreats significantly as the tide changes. At best, Rush Point acts as a headland only at high water. Although these points do not qualify as headland wake systems, and did not have as many whale sightings as the headlands, the convergence of water at Point Gustavus and the channel constriction at Rush Point may effectively provide alternate mechanisms that affect prey concentration. Using a quantitative definition of a headland wake system helps to explain negative results, should they arise. For example, the lack of an apparent relationship between tide cycle and dolphin abundance between 2 points of land (Hastie et al. 2003) may suggest that these points were not functioning as a headland wake system.

\section{Variable habitat quality among headland wake systems}

Though headlands have often been documented as exceptional habitat for marine predators, no one has yet examined the factors that may contribute to variable habitat quality among headland wakes. Point Adolphus, where we observed the greatest whale abundance, has long been noted for high abundances of humpback whales (Perry et al. 1985, Neilson \& Gabriele 2008), herring and capelin (Robards et al. 2003). Although these previous studies discuss several factors that may account for high abundances of forage fish and whales at Point Adolphus, including the high nutrient quality of water coming out of Glacier Bay, mixing along the shoreline, and a headland wake, none of these distinguishes it from our other headland wake systems. We surmise that Point Adolphus' apparently exceptional habitat quality is due in part to the fact that it produces micro-habitats characteristic of a headland wake system but without the increased current speed associated with most points of land. Faster 
currents have been suggested to decrease the longevity of eddies (Johnston \& Read 2007), and slower currents have been shown to significantly increase capture rates of salmon by harbor seals at a tidal constriction (Zamon 2001). We suggest that the comparatively slower currents at the Point Adolphus headland may allow whales to exploit the headland wake during a wider variety of tidal conditions, and help explain why whales select tideward foraging habitat more often at Point Adolphus than Point Carolus or Young Point. During large amplitude tides, there were few sightings at the faster locations at Point Carolus and very few sightings at Young Point, suggesting that currents that are too fast can make tideward habitats disadvantageous or unavailable for whale foraging.

\section{Effect of current direction on whale distribution}

Our finding that whale distribution at all 3 headlands was significantly affected by current direction corroborated previous models (Wolanski \& Hamner 1988) and observational studies (Alldredge \& Hamner 1980, Johnston et al. 2005a,b, Johnston \& Read 2007). These studies all document a preference for leeward feeding, as did most of our results (Fig. 5). However, we found a contradictory result in that tideward 'faster' waters at Point Adolphus during flood tide was the location where we sighted the most whales in the entire study. A headland wake still appears to be the major system at work at Point Adolphus, since leeward feeding is so dominant at ebb, and on the 'slower' current side of the headland, but other factors must attract whales to the tideward, faster side during flood. Shoreline topography and the influences of bathymetry on the particular forage species (Hastie et al. 2003, Zamon 2003, Cotté \& Simard 2005) seem the most likely explanatory factors, but hydroacoustic studies of changing forage fish abundance with the tide are needed to resolve this question.

\section{Effect of tidal amplitude on whale distribution}

At Point Adolphus and Point Carolus, whales appear to moderate the effect of tidal amplitude to optimize current speed by selecting slower current habitat during large amplitude tides and faster current habitat during small amplitude tides. It has been suggested that in very strong currents, such as those present during a large amplitude tide, foraging becomes too energetically demanding for either whales or their prey to be profitable (Johnston et al. 2005a). Conversely, in the weak currents during small amplitude tides, fish may be widely dispersed or have a greater ability to avoid predation. The only marginally significant relationship between whale distribution and tidal amplitude at Young Point likely reflects the wide range of current speeds available at this headland, which experiences some of the fastest currents in the Glacier Bay/Icy Strait system (Table 1). We suspect that during a large amplitude tide, currents are so strong that foraging on either side is unprofitable and whales leave the Young Point area.

\section{Future directions}

It is an important first step to demonstrate that baleen whale habitat quality varies greatly on the scale of a few kilometers or a few hours due to tidal and topographical factors, even though our understanding of the physical mechanisms of eddy formation and prey concentration remains unclear. Future studies would benefit from real-time measurements of current speed and direction, prey density and whale behavior. A better understanding of the process of physical aggregation of plankton and forage fish would help us draw firmer conclusions about humpback whale foraging behavior. Moreover, the relatively new technology for tracking the underwater movements of free-ranging whales (Croll et al. 2001, Goldbogen et al. 2008, Witteveen et al. 2008) has the potential to rapidly advance our understanding of behavioral aspects of how foraging whales exploit tidal currents in headland wake systems. Future studies should also investigate if different age/sex classes show the same overall patterns for headland foraging, for comparison with findings that smaller rorqual species may target less concentrated prey (Piatt \& Methven 1992, Friedlaender et al. 2009). Finally, it would be instructive to document tidal influences on marine predators in geographic areas with less extreme tidal variation.

It is hard to overstate the importance of foraging efficiency to marine predator survival and reproductive success; therefore, it is important to develop a better understanding of the ways that these predators exploit oceanographic features that concentrate prey. The broader conservation significance of demonstrating the importance of headland wake systems foraging to baleen whales lies in the realization that protecting such micro-scale oceanographic features from anthropogenic impacts can yield a disproportionately large biological advantage to marine predator populations. An improved understanding of how headland wake systems function will greatly enhance our ability to design and implement marine protected areas that are ecologically meaningful to baleen whales and other large marine predators. 
Acknowledgements. We thank J. Neilson, L. Etherington, P. Norwood and B. Schafer for their thoughtful comments on this manuscript. We thank N. Koehler for useful discussions on whale foraging at Point Adolphus. We thank J. Straley for allowing the use of computer software and equipment necessary for completion of the manuscript, and B. Eichenlaub for consulting on spatial analysis. This study would not have been possible without the substantial efforts of numerous Park staff, volunteers and collaborators who have contributed over the years to Glacier Bay National Park's long-term humpback whale database.

\section{LITERATURE CITED}

Alldredge AL, Hamner WM (1980) Recurring aggregation of zooplankton by a tidal current. Estuar Coast Mar Sci 10: 31-37

Baker CS, Medrano-Gonzalez L, Calambokidis J, Perry A and others (1998) Population structure of nuclear and mitochondrial DNA variation among humpback whales in the North Pacific. Mol Ecol 7: 695-707

Calambokidis J, Falcone EA, Quinn TJ, Burdin AM and others (2008) SPLASH: Structure of populations, levels of abundance and status of humpback whales in the North Pacific. Cascadia Research for U.S. Department of Commerce, Olympia, WA

Cotté C, Simard Y (2005) Formation of dense krill patches under tidal forcing at whale feeding hot spots in the St. Lawrence Estuary. Mar Ecol Prog Ser 288:199-210

Croll DA, Acevedo-Gutierrez A, Tershy BR, Urban-Ramirez J (2001) The diving behavior of blue and fin whales: Is dive duration shorter than expected based on oxygen stores? Comp Biochem Physiol A 129:797-809

Dawbin WH (1966) The seasonal migratory cycle of humpback whales. In: Norris, KS (ed) Whales, dolphins, and porpoises. University of California Press, Berkeley, CA, p 145-170

Etherington LL, Hooge PN, Hooge ER, Hill DF (2007) Oceanography of Glacier Bay, Alaska: implications for biological patterns in a glacial fjord estuary. Estuar Coasts 30:927-944

Friedlaender AS, Lawson GL, Halpin PN (2009) Evidence of resource partitioning between humpback and minke whales around the western Antarctic Peninsula. Mar Mamm Sci 25:402-415

Friedrichs CT, Aubrey DG (1988) Non-linear tidal distortion in shallow well-mixed estuaries: a synthesis. Estuar Coast Shelf Sci 27:521-545

Goldbogen JA, Calambokidis J, Croll DA, Harvey JT and others (2008) Foraging behavior of humpback whales: kinematic and respiratory patterns suggest a high cost for a lunge. J Exp Biol 211:3712-3719

> Hastie GD, Wilson B, Thompson PM (2003) Fine-scale habitat selection by coastal bottlenose dolphins: application of new land-based video-montage technique. Can J Zool 81: $469-478$

Hill DF, Ciavola SJ, Etherington L, Klaar MJ (2009) Estimation of freshwater runoff into Glacier Bay, Alaska and incorporation into a tidal circulation model. Estuar Coast Shelf Sci 82:95-107

Johnston DW, Thorne LH, Read AJ (2005a) Fin whales Balaenoptera physalus and minke whales Balaenoptera acu-

Editorial responsibility: John Piatt, Anchorage, Alaska, USA torostrata exploit a tidally driven island wake ecosystem in the Bay of Fundy. Mar Ecol Prog Ser 305:287-295

Johnston DW, Westgate AJ, Read AJ (2005b) Effects of finescale oceanographic features on the distribution and movements of harbour porpoises Phocoena phocoena in the Bay of Fundy. Mar Ecol Prog Ser 295:279-293

> Johnston DW, Read AJ (2007) Flow-field observations of a tidally driven island wake used by marine mammals in the Bay of Fundy, Canada. Fish Oceanogr 16:422-435

Krieger K, Wing BL (1984) Humpback whale prey studies in southeastern Alaska, Summer 1983. Northwest and Alaska Fisheries Center, Auke Bay Laboratory, Auke Bay, AK

> Luettich RA, Westerink JJ (1991) A solution for the vertical variation of stress, rather than velocity, in a 3-dimensional circulation model. Int J Numer Methods Fluids 12:911-928

Mendes S, Turrell W, Mendes S, Lütkebohle T, Thompson P (2002) Influence of the tidal cycle and a tidal intrusion front on the spatio-temporal distribution of coastal bottlenose dolphins. Mar Ecol Prog Ser 239:221-229

Neilson JL, Gabriele CM (2008) Results of humpback whale population monitoring in Glacier Bay and adjacent waters: 2008. Report to the National Park Service, Glacier Bay National Park and Preserve, Gustauvs, AK

Perry A, Baker CS, Herman LM (1985) The natural history of humpback whales (Megaptera novaeangliae) in Glacier Bay. Final Report to the National Park Service, Alaska Regional Office, Anchorage, AK

> Piatt JF, Methven DA (1992) Threshold foraging behavior of baleen whales. Mar Ecol Prog Ser 84:205-210

Robards M, Drew G, Piatt J, Hooge P and others (2002) Glacier Bay small schooling fish project. US Geological Service Report, Anchorage, AK

Robards M, Drew G, Piatt J, Anson JM and others (2003) Ecology of selected marine communities in Glacier Bay: zooplankton, forage fish, seabirds and marine mammals. US Geological Service Report, Anchorage, AK

> Vlietstra LS, Coyle KO, Kachel NB, Hunt Gl (2005) Tidal front affects the size of prey used by a top marine predator, the short-tailed shearwater (Puffinus tenuirostris). Fish Oceanogr 14:196-211

Wing BL, Krieger K (1983) Humpback whale prey studies in southeastern Alaska, summer 1982. Northwest and Alaska Fisheries Center, Auke Bay Laboratory, Auke Bay, AK

- Witteveen BH, Foy RJ, Wynne KM, Tremblay Y (2008) Investigation of foraging habits and prey selection by humpback whales (Megaptera novaeangliae) using acoustic tags and concurrent fish surveys. Mar Mamm Sci 24: 516-534

Wolanski E, Hamner WM (1988) Topographically controlled fronts in the ocean and their biological influence. Science 241:177-181

Wolanski E, Asaeda T, Akihiro T, Deleersnijder E (1996) Three-dimensional island wakes in the field, laboratory experiments and numerical models. Cont Shelf Res 16: 1437-1452

Zamon JE (2001) Seal predation on salmon and forage fish schools as a function of tidal currents in the San Juan Islands, Washington, USA. Fish Oceanogr 10:353-366

Zamon JE (2003) Mixed species aggregations feeding upon herring and sandlance schools in a nearshore archipelago. Mar Ecol Prog Ser 261:243-255

Submitted: April 30, 2009; Accepted: October 21, 2010

Proofs received from author(s): February 2, 2011 